\title{
Minas Gerais e sua população de deficientes: um estudo a partir dos Censos Demográficos de 2000 e 2010
}

\author{
Minas Gerais and its disabled people: a study based on the Censuses of 2000 \\ and 2010
}

\author{
Emerson Augusto Baptista \\ Doutorando em Demografia - Centro de Desenvolvimento \\ e Planejamento Regional (CEDEPLAR - UFMG) \\ emersonaug@yahoo.com.br
}

José Irineu Rangel Rigotti

Doutor em Demografia e Professor do Centro de Desenvolvimento e

Planejamento Regional (CEDEPLAR - UFMG)

rigotti@ cedeplar.ufmg.br

Artigo recebido para revisão em 05/12/2013 e aceito para publicação em 20/12/2013

\begin{abstract}
Resumo
O objetivo principal deste artigo é fazer uma análise exploratória sobre a população de deficientes no Estado de Minas Gerais utilizando duas abordagens mais gerais, quais sejam: espacial e demográfica. Para tanto, foram utilizados os dados das amostras dos Censos Demográficos de 2000 e 2010. Os resultados do censo de 2000 apontaram a existência de 24,5 milhões de brasileiros com algum tipo de deficiência, ou seja, $14,5 \%$ da população do país naquele ano. Já no censo de 2010 foram registrados 45,6 milhões de pessoas $(23,9 \%)$ com alguma das deficiências pesquisadas. Coincidentemente, o Estado de Minas Gerais apresentou algo muito próximo a essa média em ambos os censos. O que se pretende avaliar, então, são os padrões de distribuição espacial e demográfico para os tipos de deficiência propostos pelo Instituto Brasileiro de Geografia e Estatística (IBGE), por meio do mapeamento coroplético de taxas brutas padronizadas. Espera-se contribuir para o avanço de estudos relacionados à população de deficientes em Minas Gerais, no nível de municípios, pois, sendo um tema relativamente pouco explorado, acredita-se que este mapeamento revelará padrões espaciais pertinentes para o desenvolvimento e aplicação de políticas públicas que visem este segmento, bem como permitirá a elaboração de algumas hipóteses preliminares que poderão ser avaliadas em trabalhos futuros.
\end{abstract}

Palavras-chave: pessoas deficientes; geografia; demografia; distribuição espacial; Minas Gerais.

\begin{abstract}
The main goal of this article is to make an exploratory analysis on the population of disabled people in the State of Minas Gerais using two general approaches, namely: spatial and demographic. For this, we used data from sample Censuses of 2000 and 2010. The results of the 2000 census showed the presence of 24,5 million Brazilians with some kind of disability, i.e., $14,5 \%$ of the population in that year. Already in the 2010 census were registered 45,6 million people $(23,9 \%)$ with some of the deficiencies studied. Coincidentally, the State of Minas Gerais had something very close to this average in both censuses. What we want to evaluate, then, are the patterns of spatial distribution and demographics for the types of disabilities proposed by the Brazilian Institute of Geography and Statistics (IBGE), through coropletic mapping of gross rates standardized. Is expected contribute to the advancement of studies related to population of disabled people in Minas Gerais, at the level of
\end{abstract}


municipalities, because being a relatively unexplored, it is believed that this mapping reveal spatial patterns relevant to the development and implementation of public policies aimed at this segment, as well as allow the elaboration of some preliminary hypotheses that can be evaluated in future studies.

Keywords: disabled people; geography; demography; spatial distribution; Minas Gerais.

\section{INTRODUÇÃo}

A discussão em torno do termo "deficiência" tem ocupado cada vez mais espaço no dia a dia da população brasileira, seja através de políticas públicas, da mídia, etc. Isso decorre, especialmente, pelo fato da população de deficientes ter se conscientizado acerca de seus direitos, deixando de lado uma condição meramente assistencialista, e a população, de uma forma geral, ter se atentado quanto às diferenças individuais que se fazem presentes no cerne de uma sociedade.

Contudo, engana-se quem pensa que o debate acerca das questões relativas aos deficientes esteja próximo de um desfecho. $\mathrm{Na}$ vanguarda destes debates está a questão conceitual, e talvez esse seja o ponto mais importante para que uma discussão sobre essa população se inicie. Isso porque a terminologia utilizada para se referir aos deficientes tem mudado ao longo dos tempos trazendo consigo toda uma história de discriminação e marginalização que acaba por refletir nos dias de hoje. Logo, parece que a disputa pela terminologia correta dispersa energia que deveria ser aplicada em questões mais substantivas.
Portanto, este estudo voltará suas atenções e análises para questões práticas que visem ajudar e auxiliar políticas públicas, bem como novos trabalhos, de modo a contribuir para a melhora na vida dos deficientes. Embora o espaço conceitual de análise seja o Estado de Minas Gerais, a metodologia empregada pode ser replicada para todas as Unidades da Federação (UF).

A opção por Minas Gerais se justifica por esse Estado representar, em diversos estudos regionais, uma síntese do Brasil no que tange ao seu espaço heterogêneo, desigual e complexo, que, aliado às potencialidades oferecidas pelos Censos Demográficos de 2000 e 2010, permitirá a análise dos padrões espaciais no que diz respeito aos deficientes.

\subsection{Objetivos e Justificativas}

O objetivo principal deste trabalho é verificar a existência de dois tipos de padrões: o espacial e o demográfico. O primeiro busca localizar a distribuição dos deficientes no espaço em estudo, enquanto que o demográfico faz uma análise sobre os microdados dos censos relacionadas às pessoas deficientes. 
Como objetivos específicos, propõe-se:

a) Revisar a literatura no tocante à questão da população de deficientes.

b) Mapear, através de taxas padronizadas, os tipos de deficiência estudados.

Este estudo se justifica, especialmente, pela necessidade em se disponibilizar uma metodologia adequada, de forma a orientar trabalhos futuros no que tange a espacialização da população de deficientes, bem como permitir ações pelo poder público de forma mais localizada e eficaz. Além disso, a relativa escassez de trabalhos acadêmicos que contemplem a questão dos deficientes também foi determinante na definição do tema.

\section{MARCO TEÓRICO}

Pode-se afirmar que a população brasileira é composta por um contingente demográfico bastante diversificado, o que é reforçado por inúmeras informações geradas por diversas fontes de pesquisas divulgadas nos últimos anos como, por exemplo, os Censos Demográficos e as PNADs (Pesquisa Nacional por Amostra de Domicílios). Esta diversidade pode ser observada tanto nos aspectos demográficos (sexo, idade, etc.), quanto nos aspectos sócio-econômicos (renda, escolaridade, composição familiar, etc.). Portanto, estudar uma sociedade e, neste caso, a brasileira, mais especificamente um de seus grupos, torna-se um grande desafio à medida que ela possui valores culturais que se expressam no modo pelo qual ela se organiza. Estes valores refletem uma imagem do e no pensamento dos homens. Uma das principais características dos valores é a de poderem ser expressos na forma de adjetivos. Sendo assim, o termo "deficiente" é um adjetivo que, como tal, adquire valor cultural de acordo com as regras, padrões e normas estabelecidas nas relações sociais, constituindo uma categoria capaz de agrupar, numa identidade comum, diferentes tipos de pessoas.

Desta forma, a legislação brasileira define a pessoa deficiente como sendo:

\begin{abstract}
Aquela que apresenta, em caráter permanente, perdas ou anormalidades de sua estrutura ou função psicológica, fisiológica ou anatômica, que gere incapacidade para o desempenho de atividade, dentro do padrão considerado normal para o ser humano (BRASIL, 1989).
\end{abstract}

Portanto, com a incorporação deste conceito e o reconhecimento desta população como parte integrante da sociedade, tornou-se obrigatório a incorporação de questões específicas sobre a população deficiente, nos censos nacionais, conforme Lei 7.853 de 24 de outubro de 1989 (BRASIL, 2004).

Contudo, a questão da deficiência no Brasil, e porque não dizer no mundo, se remete há tempos mais longínquos, especialmente no que tange ao seu conceito, o que refletiu e interferiu, diretamente, na definição exata do número de deficientes ao longo dos anos.

Sabe-se que até meados da década de 1990, quem dominava as definições de deficiência eram os modelos médicos. Esses explicam a deficiência como sendo um conjunto 
específico de defeitos corporais, o que influenciou diretamente os levantamentos demográficos, que no Brasil reúne informações sobre deficiência desde o fim do século XIX, e as produções textuais, que trataram do assunto com maior especificidade ao longo do século XX. Embora ainda se possa notar tais influências, nos últimos anos tem-se observado uma nova maneira de se entender a deficiência: sob a ótica do modelo social. O ponto de partida deste modelo é a idéia de que a deficiência é resultante da combinação de limitações impostas pelo corpo a uma organização social pouco sensível à diversidade corporal. Em outras palavras, a deficiência não está localizada apenas nos indivíduos, mas na incapacidade de a sociedade prever e ajustar-se à diversidade. Por conta deste novo modelo, algumas mudanças já podem ser percebidas como, por exemplo, nos questionários de levantamentos $\mathrm{e}$ na interpretação da legislação de atenção aos deficientes (MEDEIROS; DINIZ, 2004).

Antes de iniciar e aprofundar uma discussão em informações mais recentes sobre as pessoas com deficiência faz-se, necessário apresentar e entender a evolução de levantamentos sobre esse segmento popula-cional.

Um grande marco sobre a questão foi a realização de um congresso ${ }^{1}$ em Londres no ano de 1860 que, dentre outras coisas, discutiu como se poderia levantar dados a respeito daquelas pessoas com “defeitos físicos”. Recomendou-se, então, seguir um modelo de classificação

\footnotetext{
1 Esse congresso posteriormente viria a se chamar
} Comissão Estatística Internacional. demográfica que foi mantido por mais de um século em diversos países. Esse identificava duas classes de "defeitos físicos": a "cegueira" e a "surdo-mudez". Posteriormente, mais precisamente em 1872 no congresso de São Petersburgo, da Comissão Estatística Internacional, expandiu-se às categorias de identificação para: "cegueira"; “surdo-mudez"; “idiotismo"; "cretinismo"; e/ou "alienação mental".

Segundo Medeiros e Diniz (2004), no Brasil, até onde se sabe e se dispõe de registro, informações sobre pessoas deficientes começaram a ser levantadas nos inquéritos de 1872, 1890 e 1900, seguindo orientações do Congresso de São Petersburgo. Já no recenseamento de 1920, o levantamento no país limitou-se àquelas categorias do Congresso de Londres que, em certa medida, foram mantidas até o censo de 1940. Uma tendência internacional foi seguida em decorrência das dificuldades em se captar com precisão as informações referentes às então denominadas espécies de demência ("idiotismo", "cretinismo" e "alienação mental"). Após o censo de 1940 um período de 41 anos transcorreu-se até que o tema "deficiência" ocupasse espaço novamente nos grandes levantamentos domiciliares brasileiros.

Sendo assim, a Pesquisa Nacional por Amostra de Domicílios (PNAD), de 1981, trouxe em seu questionário de saúde um bloco denominado "deficientes". O principal objetivo neste levantamento foi identificar pessoas com lesões corporais graves e permanentes. Com relação à Pesquisa Nacional sobre Saúde e 
Nutrição (PNSN) de 1988, essa identificou condições físicas ou mentais que podiam afetar o estado de saúde das pessoas, buscando levantar informações sobre os diferentes graus de algumas lesões.

Vale à pena destacar, ainda que como complemento às informações colocadas anteriormente e aos estudos de Medeiros e Diniz (2004), o trabalho de Neri e Soares (2004), que resgatam e analisam uma sucessão de retratos das pessoas com deficiência desde antes da libertação dos escravos no século XIX até o limiar do século XXI. O objetivo consistiu em elaborar um mapa de conhecimento sobre o universo das pessoas deficientes, de forma a subsidiar políticas e ações dos setores públicos, privados e da sociedade civil. Para isso, eles se basearam em dados secundários mais antigos, como os inquéritos de 1872 e de 1900, os censos de 1920 e de 1940, assim como o processamento de microdados no nível individual, entre os quais listam os suplementos de saúde da Pesquisa Nacional por Amostra de Domicílios (PNADs) de 1981 do IBGE e a Pesquisa de Padrões de Vida da Fundação Seade, de 1998. A ênfase do estudo, porém, recai sobre os microdados censitários de 1991 e de 2000, pois, foi a partir do primeiro que o Instituto Brasileiro de Geografia e Estatística (IBGE), atendendo o que a Lei determina, incluiu em seu questionário questões que possibilitassem verdadeiramente o conhecimento e o registro das pessoas deficientes.
Com as informações acima e o conhecimento de que entre todas as questões do censo as relativas à deficiência são as únicas obrigatórias por lei, percebe-se que nas últimas décadas, especialmente a partir dos anos de 1960 e de 1970, houve um avanço no processo de mobilização política das pessoas com deficiência na luta contra as barreiras físicas e comportamentais que impediam sua inclusão social (SASSAKI, 2002), pois, durante séculos, as pessoas que nasciam com algum tipo de deficiência, seja física, mental, sensorial, etc, não sobreviviam, ou porque tinham a vida abortada logo após o nascimento, ou por falta de recursos técnicos e científicos para uma vida prolongada.

Atualmente, um movimento organizado de pessoas com deficiência tem lutado pela equiparação de oportunidades. É possível afirmar que houve um amadurecimento desse segmento ao abandonar uma perspectiva meramente assistencialista e situar o debate relacionado às pessoas com deficiência no paradigma das políticas públicas e dos direitos humanos. A diversidade entre os indivíduos é um dado biológico, sobre o qual não há contestação. Entretanto, as diferenças de oportunidades e as desigualdades sociais decorrem das relações humanas e da concentração de poder, exigindo intervenções para que se evitem injustiças (CORTELLA, 1996). Em resumo, toda essa mobilização por parte dos deficientes trouxe à tona direitos e deveres de todos os setores da sociedade para com os mesmos. A incorporação de questões 
referentes aos deficientes nos censos nacionais, como visto, é um exemplo.

Diante do exposto até aqui, pode-se dizer que a população de deficientes só começou efetivamente a ser considerada como parte integrante da sociedade brasileira a partir da legislação de 1989, mais especificamente, com o Censo Demográfico de 1991. Para este ano o censo recenseou, aproximadamente, 2,2 milhões de pessoas com algum tipo de deficiência ${ }^{2}$, o que equivale a $1,2 \%$ da população brasileira para o ano de 1991 (JANNUZZI; JANNUZZI, 1994 apud BRASIL, 2004). De acordo com informações de Neri e Soares (2004), o valor encontrado é distribuído dentre os tipos de deficiência da seguinte forma: cegueira $(8,7 \%)$; surdez (10,6\%); deficiência mental (39,5\%); falta de membro(s) ou parte dele $(8,6 \%)$; paralisia total $(2,9 \%)$; paralisia de um dos lados do corpo (12,2\%); e paralisia nas pernas $(12,1 \%)$. Torna-se importante mencionar, ainda que apenas como referência e registro, a análise minuciosa que o trabalho de Jannuzzi e Jannuzzi (1998) faz a respeito da população de deficientes utilizando os dados do Censo Demográfico de 1991. Nele os autores discutem os resultados empíricos encontrados, além disso, levantam e argumentam sobre questões políticas que deveriam ser destinadas a essa população.

Diante dos números colocados acima, vê-se que o valor de $1,2 \%$ de deficientes encontrado no Censo Demográfico de 1991 está

\footnotetext{
${ }^{2}$ Torna-se importante mencionar que um indivíduo pode apresentar mais de um tipo de deficiência, mas que ele só é contabilizado uma única vez.
}

muito abaixo dos valores estimados pela Organização Mundial de Saúde (OMS), pois essa coloca que aproximadamente $10,0 \%$ da população de um país possui algum tipo de deficiência. Ainda em relação a este valor a Carta para o terceiro milênio ${ }^{3}$ de 1999 reforça que além de " $10,0 \%$ de qualquer sociedade nascer com - ou adquirir - uma deficiência, aproximadamente uma em cada quatro famílias possui uma pessoa com deficiência”.

Jannuzzi e Jannuzzi (1994), citado por Brasil (2004), tentam explicar o baixo percentual de deficientes encontrados no censo de 1991. Segundo eles, na metodologia utilizada podem ser detectados alguns pontos que justifiquem o baixo valor registrado em relação à população em geral. Estes pontos seriam:

o conceito de deficiências adotado pelo IBGE, o que engloba apenas os grandes lesados e os que tenham passado por algum tipo de diagnóstico (clínico, pedagógico, etc.); o provável ocultamento por parte dos informantes, fruto do preconceito que envolve a questão das deficiências, no Brasil; e as dificuldades do pesquisador em identificar deficiências.

Os questionamentos levantados sobre o conceito que o IBGE utilizou para o recenseamento da população de deficientes no censo de 1991 proporcionou uma intensa discussão e uma busca objetiva para se definir qual seria a melhor forma de se obter dados condizentes com a realidade brasileira. Para tanto, o Censo Demográfico de 2000 adotou, e

\footnotetext{
${ }^{3}$ Esta Carta foi aprovada no dia 9 de setembro de 1999, em Londres, Grã-Bretanha, pela Assembléia Governativa da REHABILITATION INTERNATIONAL, estando Arthur O'Reilly na Presidência e David Henderson na Secretaria Geral.
} 
que fora mantido no censo de 2010, "um conceito ampliado de deficiências, que inclui a percepção que as pessoas pesquisadas têm em relação às alterações provocadas pela deficiência na sua capacidade de realização, comportamento e participação social" (BRASIL, 2004). Além disso, atribuiu-se o título de pessoa deficiente não somente àquelas consideradas incapazes, mas também às pessoas que reportaram possuir grande ou alguma dificuldade permanente de enxergar, ouvir e caminhar e subir escadas, fato não observado nos inquéritos domiciliares passados. $\mathrm{O}$ conceito adotado a partir do censo de 2000 é, portanto, similar ao utilizado pela OMS e recomendado pelas Nações Unidas. Esta padronização terminológica e conceitual possibilitará que os estudos levantados em qualquer parte do mundo sejam passíveis de comparações estatísticas.

A nova estrutura do questionário do censo dedica cinco e quatro questões ao tema da deficiência em 2000 e 2010, respectivamente, e não apenas uma como em 1991, seguindo modernos e adequados preceitos de preservar a liberdade de expressão dos sujeitos entrevistados sobre sua situação e do meio em que está inserido. A resposta não cabe ao recenseador, mas ao entrevistado baseado na sua subjetividade. Ele é demandado a levar em conta em sua resposta o efeito do acesso a instrumentos para lidar com deficiências como óculos, próteses, aparelhos de audição, etc (NERI; SOARES, 2004).
Contudo, e segundo Medeiros e Diniz (2004), apesar do consenso entre os especialistas no assunto de que a forma de captação das informações nos dois últimos censos seja muito mais apropriada para o estudo da deficiência que a dos censos anteriores, que se limitavam a catalogar um número restrito de "defeitos físicos e mentais", o julgamento das dificuldades pelos respondentes já foi acusado de produzir informação "subjetiva", enquanto a identificação dos "defeitos" produz informação "objetiva".

Sendo assim, e mesmo que ainda haja questionamentos quanto ao questionário do censo que, como visto, é similar ao utilizado pela OMS e recomendado pelas Nações Unidas, a ONU apresentou dados do início do milênio, quando o mundo abrigaria cerca de 500 milhões de pessoas com deficiência, das quais $80,0 \%$ viveriam em países em desenvolvimento. No Brasil, o censo de 2000 registrou 24,5 milhões de pessoas com algum tipo de deficiência, ou seja, $14,5 \%$ da população do país. Já o censo de 2010 apontou que 45,6 milhões de pessoas $(23,9 \%)$ residentes no território brasileiro possuem alguma das deficiências pesquisadas. Nota-se que os números são bastante superiores aos levantamentos anteriores, menos de 2,0\%.

De acordo com Neri e Soares (2004), “isto não decorre do aumento da incidência de deficiências, mas da mudança dos instrumentos de coleta de informações, em obediência às últimas recomendações da Organização Mundial da Saúde (OMS)”. 
Portanto, com os dados colocados anteriormente a respeito da população de deficientes no Brasil, constata-se que o mesmo está acima da média mundial, sendo que o aumento desta população no país está diretamente ligado à idade. Sabe-se que a população brasileira está a se tornar cada vez mais envelhecida e isso é um problema à medida que ocasionará o surgimento de um novo elenco de demandas para atender às necessidades específicas deste grupo (IBGE, 2005). Uma discussão interessante onde os temas envelhecimento e deficiência são aproximados pode ser visto nos trabalhos de Medeiros e Diniz (2004) e Neri e Soares (2004).

Além dos problemas de uma população brasileira envelhecida, que poderá elevar o número de pessoas com deficiência, outro aspecto também preocupa. No Brasil, articulações multidisciplinares e intersetoriais que vêm sendo buscadas e que visam à instituição de políticas de prevenção, reabilitação e integração da população de deficiente às atividades sociais, quase sempre esbarram em problemas ligados à ausência de mecanismos de coleta, organização e divulgação de informações nessa área.

A disponibilidade de informações sobre as pessoas deficientes tem tido uma melhora significativa, especialmente por conta dos censos do IBGE, como citado anteriormente. Ainda assim, a classificação utilizada para determinar em qual das variáveis utilizadas pelo IBGE o indivíduo se inclui fornece margens para severas críticas por parte de diversas áreas do conhecimento e é um assunto que está longe de ser resolvido. No entanto, vale ressaltar, e isso já pode ser constatado, que os estudos caminham para resultados mais aceitáveis. Um exemplo disso pode ser visto em IBGE (2005). Segundo informações do Instituto Brasileiro de Geografia e Estatística, os homens predominam no caso de deficiência mental, auditiva e física (especialmente no caso de falta de membro ou parte dele). O resultado é compatível com o tipo de atividade desenvolvida por eles e com o risco de acidentes de diversas causas. Já a predominância de mulheres com dificuldades motoras (incapacidade de caminhar ou subir escadas) ou visuais é coerente com a composição por sexo da população idosa, com o predomínio de mulheres a partir dos 60 anos. Portanto, elas são maioria entre as pessoas com deficiência, influenciada pela maior longevidade feminina.

Tendo em vista estes estudos e as questões levantadas, optou-se por fazer uma análise da situação dos deficientes no Estado de Minas Gerais. Optou-se por esta Unidade da Federação, pois, assim como o país, trata-se de um espaço heterogêneo, desigual e complexo, que, no entanto, pode ser mais bem compreendido, haja vista as potencialidades oferecidas para análise através dos dados dos Censos Demográficos de 2000 e 2010. Além disso, verificou-se que, coincidentemente, Minas Gerais apresenta uma proporção de pessoas com deficiência muito próxima à média do país. Ou seja, há um universo de aproximadamente 2,6 milhões de indivíduos 
para analisar em 2000 e 4,4 milhões em 2010, conforme pode ser observado na Tabela 1, que apresenta ainda informações sobre o número de pessoas por tipo de deficiência ${ }^{4}$ encontrados nos censos e a taxa de crescimento observada entre os mesmos.

Espera-se, portanto, contribuir para o avanço dos estudos relacionados aos deficientes no Estado de Minas Gerais (no nível de municípios), pois sendo um tema relativamente pouco explorado e estudado no meio acadêmico, acredita-se que o mapeamento, análises e discussões apresentarão novas visões acerca da realidade dos deficientes, bem como permitirá a elaboração de algumas hipóteses preliminares que poderão ser avaliadas em trabalhos futuros.

\section{MÉTODOS E TÉCNICAS}

Neste capítulo far-se-á a descrição do método e técnicas utilizadas para responder aos objetivos propostos. Inicialmente é apresentado como as variáveis utilizadas neste trabalho se encontram nos Censos Demográficos de 2000 e 2010 e como o IBGE define as pessoas deficientes para cada variável. A seguir faz-se um breve relato de como foi feito o tratamento dos dados disponíveis nos censos e as informações que foram possíveis de se extrair. A subseção seguinte mostra a necessidade de se fazer uma padronização como forma de eliminar o efeito da composição etária sobre as variáveis, permitindo, assim, que as mesmas sejam

\footnotetext{
${ }^{4}$ Os tipos de deficiência, para ambos os censos, serão discutidos no próximo capítulo.
}

passíveis de comparação. Por último, descrevese como foi feito a confecção dos mapas e o nível de análise que será trabalhado.

\subsection{Variáveis}

O Censo Demográfico de 2000 do IBGE traz cinco variáveis que retratam questões sobre as pessoas deficientes. Estas variáveis são: "problema mental/intelectual permanente"; "capacidade de enxergar"; "capacidade de ouvir"; "capacidade de caminhar e subir/escadas"; e "deficiências". Em contrapartida, o Censo Demográfico de 2010 recenseou os quatro primeiros tipos de deficiência mencionados acima, excluindo, em relação ao Censo de 2000, a deficiência denominada "deficiências".

Para a variável problema mental/intelectual permanente o censo trouxe as seguintes categorias de respostas: "sim" ou "não". Portanto, as pessoas que responderam "sim" para esta variável são aquelas consideradas deficientes mentais.

Já as variáveis capacidade de enxergar, ouvir e caminhar/subir escadas possuem as mesmas categorias de respostas nos Censos Demográficos de 2000 e 2010, quais sejam: "incapaz", "grande dificuldade permanente" ou "alguma dificuldade permanente". O que a OMS e as Nações Unidas consideram deficientes para essas três variáveis e que o IBGE registrou nos censos demográficos de 2000 e 2010 é a soma dessas respostas. 
Por último, apresenta-se a variável deficiências, presente apenas no Censo de 2000 (por se tratar de um estudo comparativo, a mesma não será analisada neste trabalho). Para esse caso, assim como nas três variáveis anteriores, o IBGE agrega categorias de respostas para se definir o número de deficientes. Entretanto, as categorias de no Censo de 2000.

Tabela 1: População por tipo de deficiência e taxa de crescimento observada - Minas Gerais, 2000 e 2010

\begin{tabular}{c|ccc}
\hline Minas Gerais & $\begin{array}{c}\text { Censo Demográfico } \\
\text { 2000 }\end{array}$ & $\begin{array}{c}\text { Censo Demográfico } \\
\mathbf{2 0 1 0}\end{array}$ & $\begin{array}{c}\text { Taxa de Crescimento } \\
\text { (a.a.) }\end{array}$ \\
\hline População total & 17.905 .110 & 19.597 .360 & 0,90 \\
População total de deficientes & 2.667 .714 & 4.432 .186 & 5,08 \\
Deficientes visuais & 1.704 .535 & 3.339 .697 & 6,73 \\
Deficientes em capacidade de & 929.993 & 1.378 .233 & \\
caminhar e subir escadas & 662.928 & 1.001 .274 & 4,93 \\
Deficientes auditivos & 351.771 & 300.674 & $-1,57$ \\
$\quad$ Deficientes mentais & 152.196 & $\mathrm{x}$ & $\mathrm{x}$ \\
Deficientes com paralisias e/ou falta & & & \\
de membros & & & \\
\hline
\end{tabular}

Fonte: Instituto Brasileiro de Geografia e Estatística (IBGE). Censos Demográficos de 2000 e 2010

\subsection{Dados}

Utilizando os microdados do IBGE e o software SPSS 18.0 foi possível levantar, avaliar e fazer o tratamento estatístico das variáveis escolhidas para este trabalho. Portanto, informações como: total de deficientes por município; taxas brutas padronizadas de deficientes por município; frequência das variáveis separadamente por grupos etários, também em nível municipal, etc, foram possíveis de serem analisadas e mapeadas.

\subsection{Padronização}

Quando há necessidade de se comparar diferenciais de níveis a partir de taxas brutas ou gerais de variáveis que possuem uma relação estreita com a idade, torna-se necessário eliminar o efeito da composição etária, ajustando-as segundo uma mesma distribuição etária padrão. Essa técnica é chamada de padronização "e permite controlar ou isolar o efeito de determinadas características que estejam afetando a comparação, através de medidas-síntese, dos níveis de uma variável 
entre populações diferentes" (CARVALHO et al., 1994).

A padronização pode ser feita de duas maneiras: direta ou indiretamente. Qual das duas utilizar dependerá das informações de que se dispõe.

Neste estudo optou-se por utilizar a padronização direta. Portanto, para maiores detalhes sobre padronização indireta, e mesmo sobre padronização direta, ver Carvalho et al., 1994.

O cálculo de taxas brutas padronizadas por idade, pelo método direto, requer que se disponha do total de eventos, distribuídos por grupos de idade, e da distribuição etária das populações em estudo. De posse destas informações, pode-se estimar taxas específicas por idade que, aplicadas a uma distribuição etária padrão, fornecerão taxas brutas padronizadas, que podem ser comparadas para análise de diferencial de níveis entre várias populações, ou para a mesma população, ao longo de determinado período de tempo. Essa comparação é possível porque, neste caso, todas as taxas referem-se a uma única distribuição etária (padrão). As diferenças entre elas serão explicadas, em princípio, pelas diferenças entre as diversas funções da variável em estudo (conjunto de taxas específicas) (CARVALHO et al., 1994).

Para este trabalho a estrutura etária padrão utilizada foi a do Estado de Minas Gerais no ano de 2000. Desta forma, foi possível comparar as taxas brutas obtidas por município para concluir sobre os diferenciais de níveis das variáveis aqui estudadas, uma vez que refletiram apenas as diferenças reais nas taxas específicas das variáveis nas populações analisadas.

Portanto, utilizando a técnica de padronização direta é como se as taxas brutas das várias populações dos municípios do Estado de Minas Gerais tivessem exatamente a mesma composição etária, porém cada qual mantendo suas próprias taxas específicas.

\subsection{Mapas}

No intuito de conhecer e analisar a distribuição espacial dos tipos de deficiência para Minas Gerais, este estudo utiliza o nível de município como ponto de partida para se conhecer os deficientes no Estado. A utilização do nível municipal é de suma importância, pois com ele corre-se um risco menor de se mascarar certos aspectos relacionados à heterogeneidade socioeconômica do Estado, o que poderia acontecer com maior facilidade se fosse utilizada uma área de estudo agregada. Todavia, as mesorregiões são utilizadas como auxílio às análises.

Mapas coropléticos foram confeccionados no software ArcGis 10.0. Vale ressaltar, ainda, que o método de classificação utilizado nos mapas coropléticos foi o chamado Natural Break. A escolha desse método de classificação justifica-se, dentre outras coisas, por se aproximar mais dos objetivos traçados para este trabalho. Contudo, informações adicionais e mais detalhadas sobre métodos de classificação podem ser encontradas em Jenks e Caspall (1971).

Sendo assim, diversos mapas foram elaborados até se chegar aos que serão apresentados a seguir. Contudo, torna-se importante e extremamente necessário mencionar a verdadeira relevância do uso de mapas 
para trabalhos como esse, pois, mais do que a questão estética, estes mapas conseguem revelar aspectos importantes que talvez fossem mais difíceis ou impossíveis de se enxergar se utilizasse somente o dado "puro".

\section{ANÁLISE E DISCUSSÃO DOS RESULTADOS}

Inicialmente é apresentada a população total de deficientes para o Estado de Minas Gerais, anos de 2000 (figura 1) e 2010 (figura 2). Conforme se pode observar, para ambos os censos a população total de deficientes acompanha a distribuição da população total do Estado. Ou seja, os dez municípios mais populosos de Minas Gerais, segundo os Censos Demográficos de 2000 e 2010, (Belo Horizonte, Contagem, Betim e Ribeirão das Neves, localizados na região central; Uberlândia e Uberaba, no Triângulo Mineiro; Juiz de Fora na Zona da Mata; Montes Claros na porção Norte; e Governador Valadares e Ipatinga, no Leste) são também aqueles municípios que possuem as maiores populações de deficientes.

Verificou-se, ainda, que entre os censos analisados houve um aumento do número de pessoas deficientes em grande parte dos municípios, mais especificamente em 92,8\% deles. Em Belo Horizonte, por exemplo, foram registrados 550.997 pessoas com algum tipo de deficiência no Censo de 2010, ante os 277.507 indivíduos recenseados em 2000. Esse valor representa um aumento de 98,6\% no período, a uma taxa de crescimento anual observada de $6,86 \%$.

$\mathrm{Na}$ figura 3 é mostrada a diferença (2010/2000) entre as taxas brutas padronizadas para as deficiências estudadas. Pode-se observar que não há um padrão claro de distribuição espacial. Alguns aglomerados como nas porções sudoeste da mesorregião do Triângulo/Alto Paranaíba, sul da Sul/Sudoeste de Minas, nordeste da Oeste de Minas, noroeste do Norte de Minas e em uma faixa oeste que se estende de norte a sul do município de Belo Horizonte exibiram um ganho percentual expressivo de pessoas deficientes na última década.

Já aqueles municípios que apresentaram as maiores perdas no período se distribuem de forma aleatória por todo o Estado. Vale ressaltar que as mesorregiões Central Mineira, Vale do Jequitinhonha, Vale do Mucuri e pontal do Triângulo/Alto Paranaíba, regiões estagnadas socioeconomicamente se comparado com outras regiões mineiras, e que nos estudos de Baptista (2009), analisando o Censo Demográfico de 2000, se destacaram como aquelas com os maiores valores percentuais de pessoas com deficiência, estão entre as que obtiveram os menores ganhos relativos no período 2010/2000. 


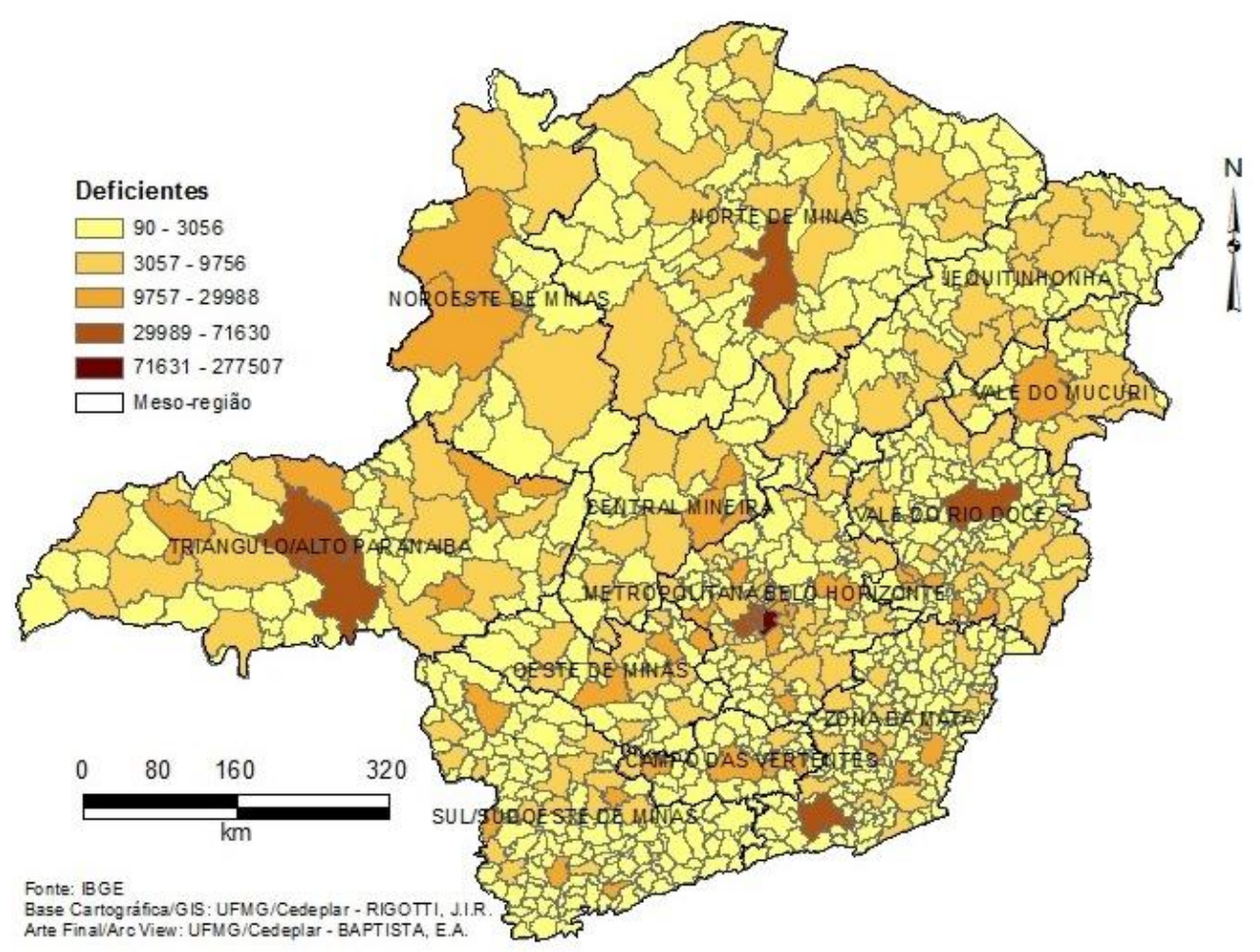

Figura 1: Total de deficientes por município - Minas Gerais - 2000

Fonte: Instituto Brasileiro de Geografia e Estatística (IBGE). Censo Demográfico de 2000

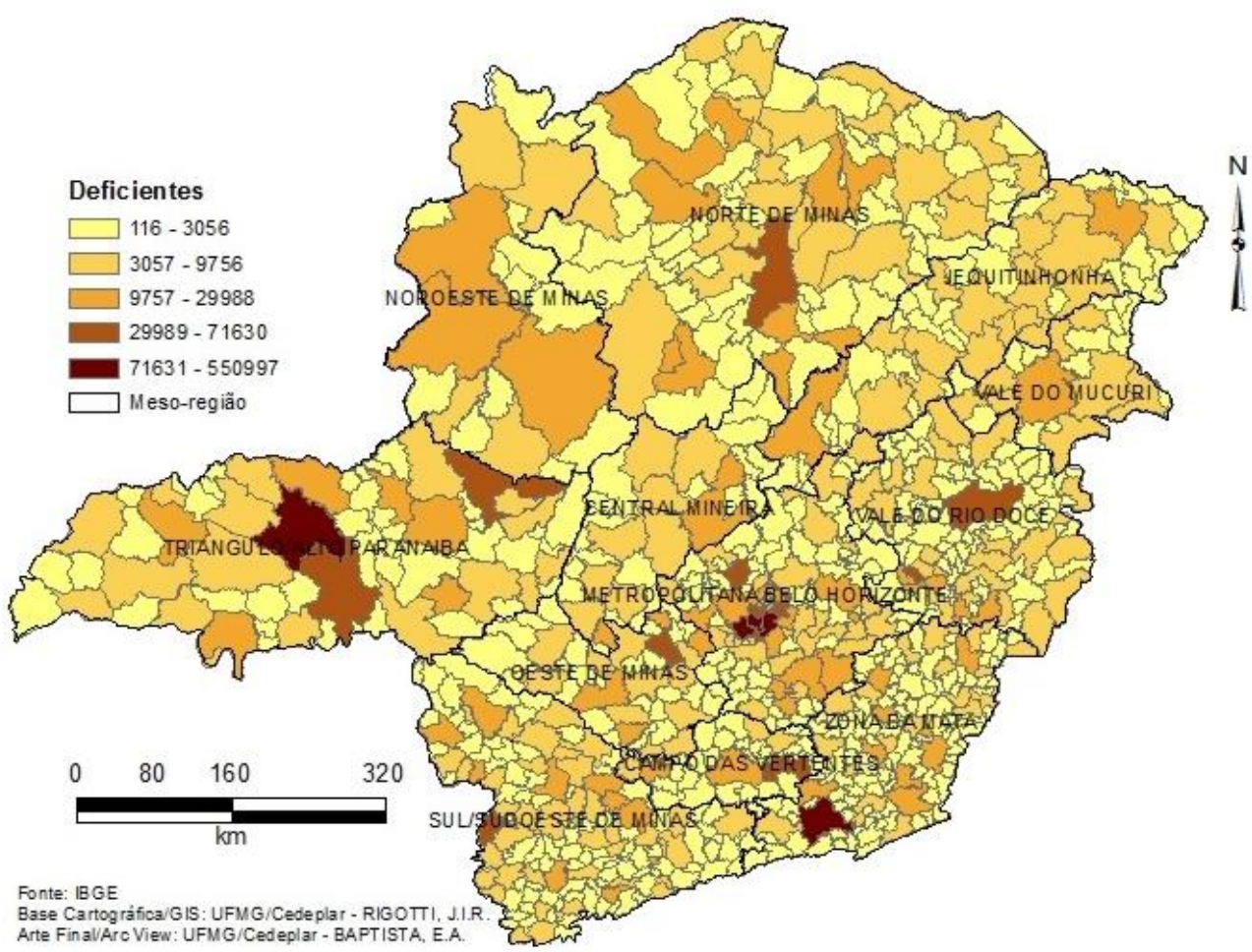

Figura 2: Total de deficientes por município - Minas Gerais - 2010

Fonte: Instituto Brasileiro de Geografia e Estatística (IBGE). Censo Demográfico de 2010

Os municípios que se destacam com os Mineira) com 54,58\%; Silveirânia (Zona da maiores ganhos são: Morro da Garça (Central Mata) com 47,65\%; e Berizal (Norte de Minas) 
com 47,03\%. Já os municípios que obtiveram as maiores perdas são: Canaã (Zona da Mata) com 21,62\%; Fruta do Leite (Norte de Minas) com 15,24\%; e São João do Oriente (Vale do Rio Doce) com 12,11\%. A maior população entre esses municípios, de acordo com os dados do Censo Demográfico de 2010, é de 7.875 habitantes em São João do Oriente. Já Morro da Garça possui uma população de 2.655 habitantes. Por se tratar de municípios de pequeno tamanho populacional, sujeitos a expressivas flutuações nas taxas, estes resultados devem ser vistos com cautela.

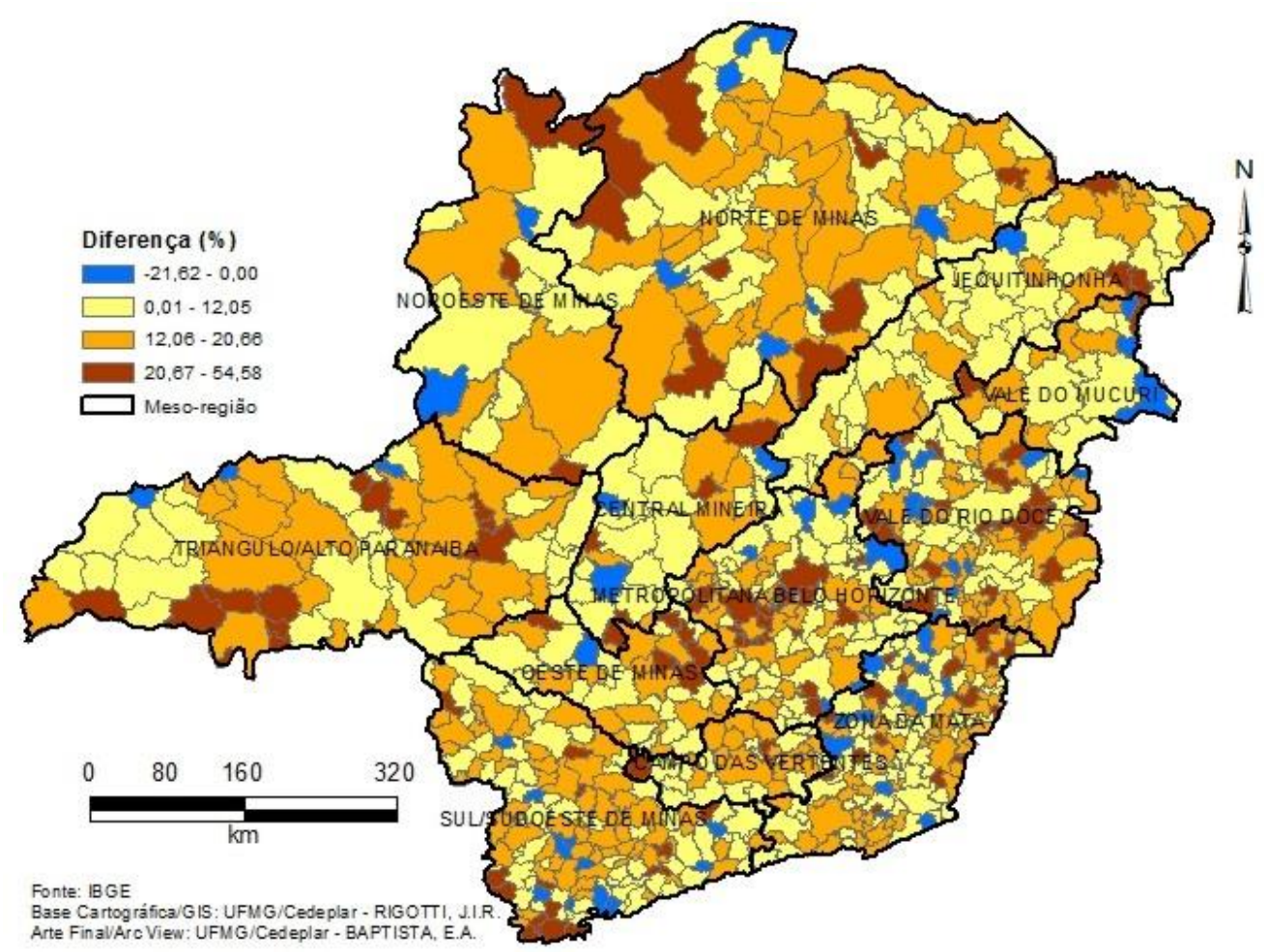

Figura 3: Diferença entre as Taxas Brutas Padronizadas de deficientes por Município - Minas Gerais - 2010/2000 Fonte: Instituto Brasileiro de Geografia e Estatística (IBGE). Censos Demográficos de 2000 e 2010

As próximas figuras retratarão as deficiências individualmente, segundo as variáveis encontradas nos Censos Demográficos de 2000 e 2010. Para cada uma delas será apresentado e analisado um mapa com a diferença entre as taxas brutas padronizadas por idade (TBP), como realizado na análise anterior.

A primeira deficiência a ser analisada é a visual. Os dados sobre a população de deficientes que foram extraídos do Censo apontam e confirmam a deficiência visual como sendo aquela que possui o maior número de casos (Tabela 1). Portanto, na figura 4 tem-se a distribuição espacial da diferença entre as taxas brutas padronizadas por idade (TBP) para esses deficientes. O que se pode observar é que, novamente, não há um padrão claro de distribuição espacial. Alguns aglomerados como os encontrados na porção sudoeste e leste da mesorregião do Triângulo/Alto Paranaíba, sul da Sul/Sudoeste de Minas, nordeste da Oeste de Minas, uma faixa que contorna a região oeste a 
sul do município de Belo Horizonte e a porção sul e norte da mesorregião Norte de Minas mostraram um ganho percentual maior de pessoas com deficiência visual no período analisado. Já os municípios que apresentaram as maiores perdas no período se distribuem, mais uma vez, de forma aleatória por todo o Estado. Portanto, é este tipo de deficiência que mais contribui para o padrão espacial geral, mostrado na Figura 3.

As regiões com maiores ganhos percentuais para deficiência visual são: Morro da Garça (Central Mineira) com 29,48\%; Silveirânia (Zona da Mata) com 28,88\%; e Berizal (Norte de Minas) com 27,89\%, ou seja, são os mesmos da análise anterior, quando as deficiências ainda não haviam sido desagregadas. No que tange aos municípios com as maiores perdas percentuais, destaca-se: Canaã (Zona da Mata) com 12,28\%; Catas Altas da Noruega (Metropolitana de Belo Horizonte) com 7,09\%; e Nova Belém (Vale do Rio Doce) com 5,69\%. A maior população entre esses municípios, segundo dados do Censo Demográfico de 2010, é de 4.630 habitantes em Canaã.

A distribuição da diferença entre as taxas brutas padronizadas por idade para a deficiência capacidade de caminhar e subir escadas, como pode ser observado na figura 5, não apresenta um padrão espacial claro. Algumas mesorregiões, Sul/Sudoeste de Minas, Zona da Mata, Vale do Rio Doce e Norte de Minas, apresentaram um ganho percentual maior de pessoas com este tipo de deficiência se comparado às demais regiões. No que diz respeito aos municípios que obtiveram perdas no período analisado, a distribuição espacial se mostrou, mais uma vez, aleatória para todo o estado.

Os municípios que se destacam com os ganhos mais significativos são: Morro da Garça (Central Mineira) com 13,63\%; Santa Rita de Minas (Zona da Mata) com 11,46\%; e Silveirânia (Zona da Mata) com 10,79\%. Já os municípios com as maiores perdas percentuais são: Canaã (Zona da Mata) com 5,77\%; Biquinhas (Central Mineira) com 5,04\%; e Córrego Novo (Vale do Rio Doce) com 4,45\%. A maior população entre esses municípios é de 6.552 habitantes em Santa Rita de Minas.

$\mathrm{Na}$ figura 6 tem-se a distribuição espacial da diferença entre as TBP's por idade para os deficientes auditivos. Observa-se que tanto os municípios que apresentaram um ganho percentual maior de pessoas com este tipo de deficiência como aqueles locais que mostraram as maiores perdas estão espalhados aleatoriamente no espaço, ou seja, novamente não existe um padrão claro de distribuição espacial. Para os deficientes auditivos, assim como ocorreu para as deficiências analisadas anteriormente, as mesorregiões que se destacaram como aquelas com os maiores valores percentuais de pessoas com deficiência no censo de 2000 estão entre as que obtiveram os menores ganhos relativos no período (2010/2000). 


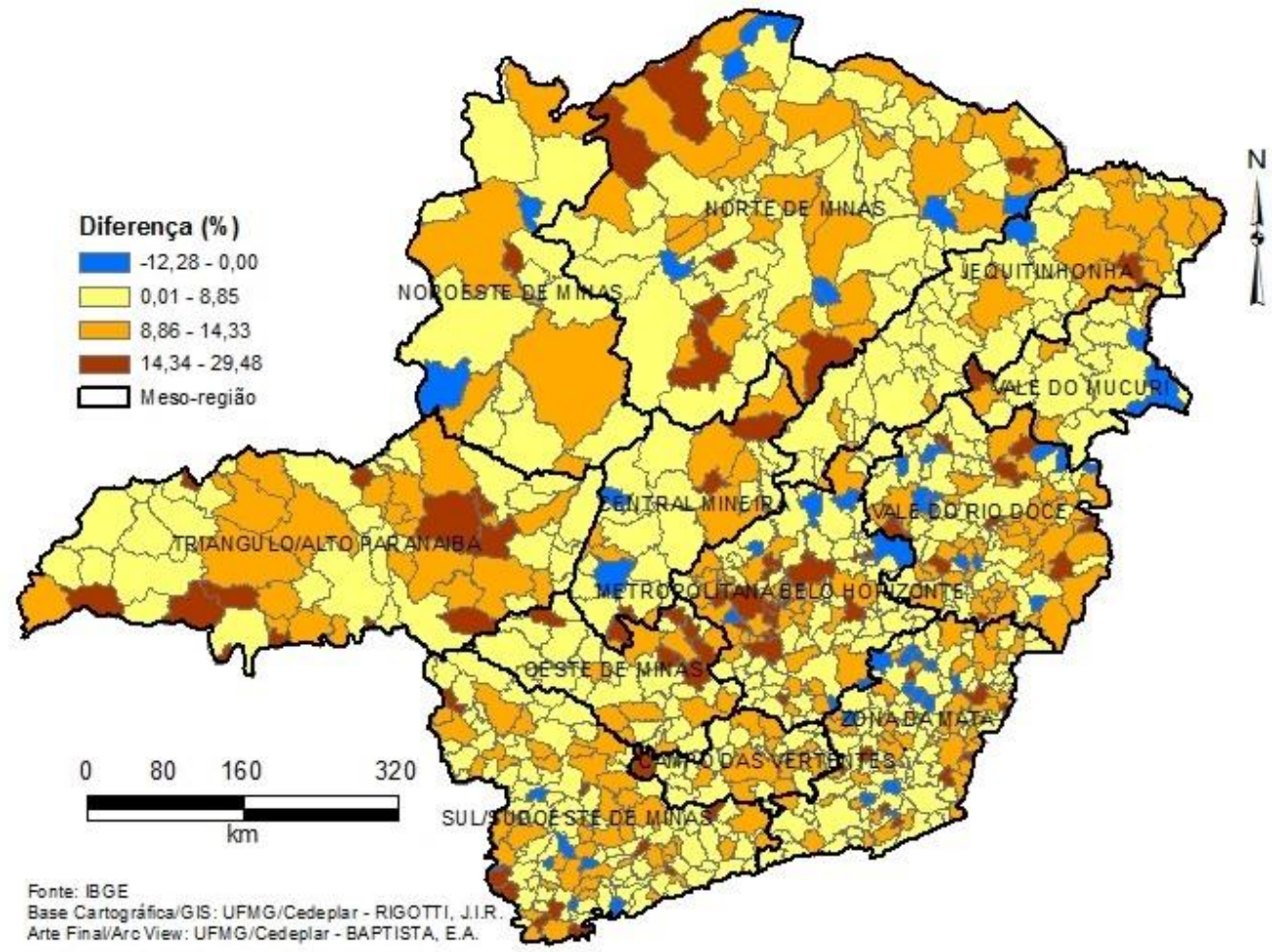

Figura 4: Diferença entre as Taxas Brutas Padronizadas de deficientes visuais por Município Minas Gerais - 2010/2000 Fonte: Instituto Brasileiro de Geografia e Estatística (IBGE). Censos Demográficos de 2000 e 2010

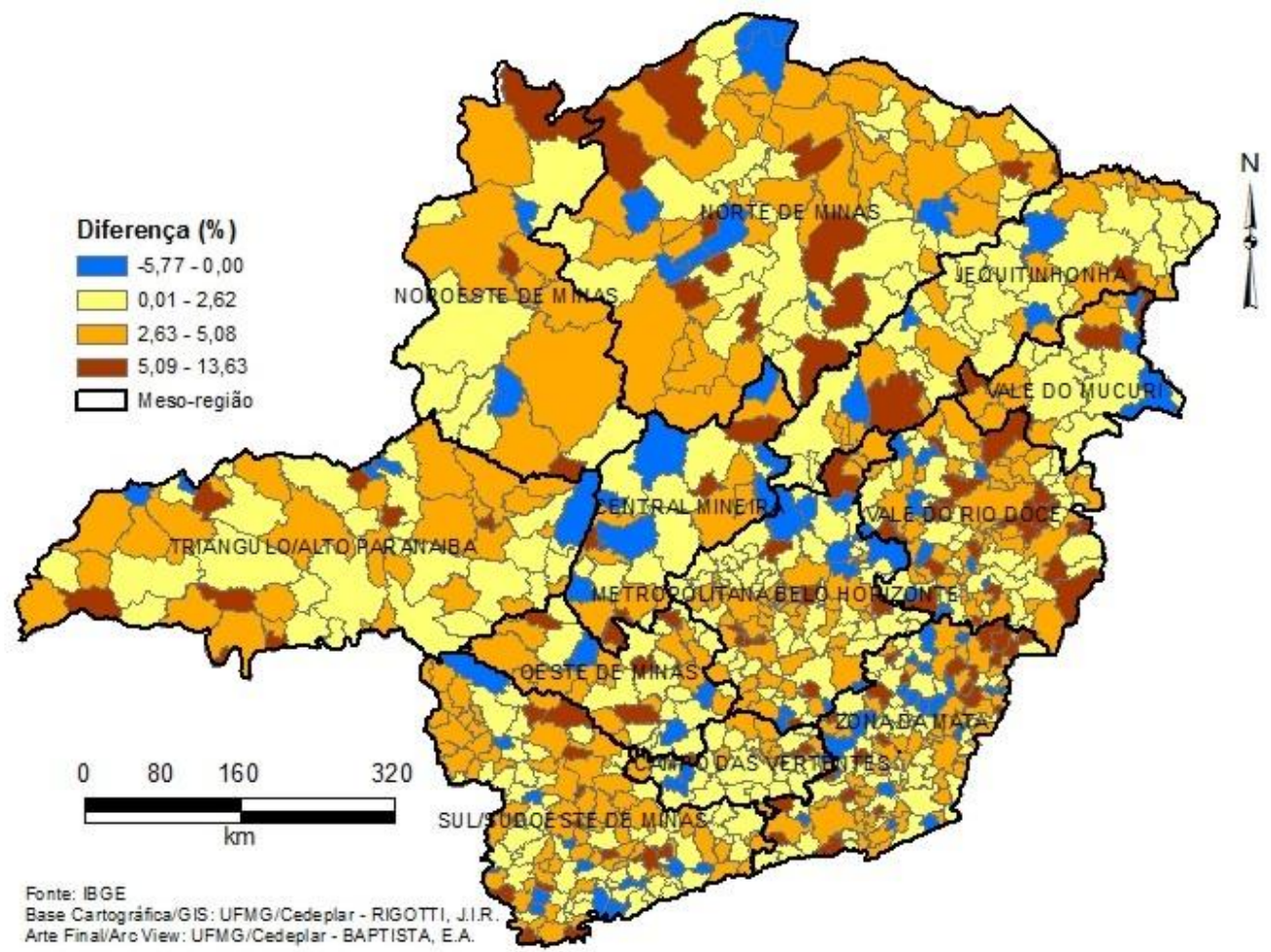

Figura 5: Diferença entre as Taxas Brutas Padronizadas de deficientes com capacidade de caminhar e subir escadas por município - Minas Gerais - 2010/2000

Fonte: Instituto Brasileiro de Geografia e Estatística (IBGE). Censos Demográficos de 2000 e 2010 
Dentre os municípios que se destacaram com os maiores ganhos estão: Cascalho Rico (Triângulo/Alto Paranaíba) com 9,89\%; Morro da Garça (Central Mineira) com 9,50\%; e Silveirânia (Zona da Mata) com 8,41\%. Percebe-se que os municípios de Morro da Garça e Silveirânia apareceram sempre entre os três valores mais altos para as deficiências analisadas até o presente momento. Isso, de certa forma, já havia sido detectado quando as deficiências foram vistas sem a desagregação (figura 3).

No que tange aos municípios com as maiores perdas percentuais para a deficiência auditiva, destaca-se: Umburatiba (Vale do Mucuri) com 3,77\%; Biquinhas (Central Mineira) com 3,02\%; e Consolação (Sul/Sudoeste de Minas) com 2,72\%. A maior população entre os municípios mencionados, segundo dados do censo de 2010, é de 2.854 habitantes em Cascalho Rico.

A figura 7 traz a distribuição espacial da diferença entre as TBP's por idade para os deficientes mentais. Nota-se que no período analisado a maioria dos municípios apresentou perda percentual, mais especificamente $66,2 \%$ deles. Novamente não foi possível detectar um padrão de distribuição espacial para os maiores ganhos e perdas, pois ambos estão espalhados de forma aleatória por todo o estado.

Os municípios que apresentaram os maiores ganhos foram: Setubinha (Vale do Jequitinhonha) com 4,57\%; Divino (Zona da Mata) com 2,97\%; e Estrela-d'Alva (Zona da Mata) com 2,87\%. Já os municípios com as maiores perdas percentuais foram: Pratinha (Triângulo/Alto Paranaíba) com 5,29\%; Fruta de Leite (Norte de Minas) com 4,74\%; e Espírito Santo do Dourado (Sul/Sudoeste de Minas) com 4,51\%.

\section{DISCUSSÃO E CONSIDERAÇÕES FINAIS}

Os estudos sobre as pessoas deficientes no Estado de Minas Gerais, e mesmo no Brasil, são ainda incipientes. Ao abordar esta temática, tomou-se o cuidado de buscar fontes que se complementassem, baseando-se este estudo, principalmente, nos dados dos levantamentos censitários realizado pelo IBGE, nos anos de 2000 e 2010. A metodologia utilizada para obtenção e tratamento dos dados foi desenvolvida a partir de uma ampla revisão bibliográfica, mesmo se tratando de um tema no qual ainda se mostre escassez de material para pesquisa. Além disso, torna-se importante salientar que novas discussões e considerações podem ser levantadas, além das análises preliminares realizadas. Observou-se ao longo do estudo que a questão da deficiência, especialmente no que tange a seu conceito, refletiu e interferiu diretamente na definição exata do número de pessoas deficientes ao longo dos anos.

O aperfeiçoamento nos instrumentos de coleta permitiu abarcar um número maior de deficientes em seus diferentes tipos e graus de limitações. Inclusive é consenso entre os especialistas no assunto que a maneira de captação de informações dos censos de 2000 e 
2010 é muito mais apropriada para o estudo da deficiência que a de censos anteriores, que limitavam a catalogar um número restrito de “defeitos físicos e mentais". Contudo, e como pôde ser visto nos resultados apresentados, houve um aumento expressivo no percentual de deficientes recenseados no censo de 2010 (23,9\%) se comparado ao de 2000 (14,5\%), contrariando, inclusive, os valores considerados como "normais" pela Organização Mundial de Saúde (OMS), ou seja, de que aproximadamente $10,0 \%$ da população de um país possui algum tipo de deficiência. A justificativa mais plausível encontrada para explicar este aumento está na forma de interpretação do questionário da amostra por parte dos respondentes, visto que outras hipóteses levantadas e analisadas não foram corroboradas. Embora a essência das perguntas tenha permanecido a mesma, a forma como essas foram feitas no censo de 2010 se diferencia um pouco da maneira como foi perguntado no Censo de 2000. Toma-se, por exemplo, a deficiência visual. Em ambos os censos foi pedido ao entrevistado que avaliasse sua capacidade de enxergar; caso a pessoa usasse óculos ou lentes de contato, a avaliação foi feita enquanto os estivesse usando. Sendo assim, no Censo de 2000 havia as seguintes opções: 1 - incapaz (pessoa que se declarou totalmente cega); 2 - grande dificuldade permanente (pessoa que se declarou com grande dificuldade permanente para enxergar, mesmo com o uso de óculos ou lentes de contato); 3 alguma dificuldade permanente (pessoa que se declarou com alguma dificuldade permanente para enxergar, mesmo com uso de óculos ou lentes de contato); e 4 - nenhuma dificuldade (pessoa que se declarou sem nenhuma dificuldade permanente para enxergar, ainda que isto exija o uso de óculos ou lentes de contato). Já o Censo Demográfico de 2010 trouxe as seguintes opções de resposta: 1 - não consegue de modo algum (para a pessoa que declarou ser permanentemente incapaz de enxergar); 2 - grande dificuldade (para a pessoa que declarou ter grande dificuldade permanente de enxergar, ainda que usando óculos ou lentes de contato); 3 - alguma dificuldade (para a pessoa que declarou ter alguma dificuldade permanente de enxergar, ainda que usando óculos ou lentes de contato); e 4 - nenhuma dificuldade (para a pessoa que declarou não ter qualquer dificuldade permanente de enxergar, ainda que precisando usar óculos ou lentes de contato). Enfim, essas pequenas alterações podem eventualmente ter provocado esse aumento significativo no percentual de pessoas deficientes, tanto para o Brasil como para o próprio Estado. 


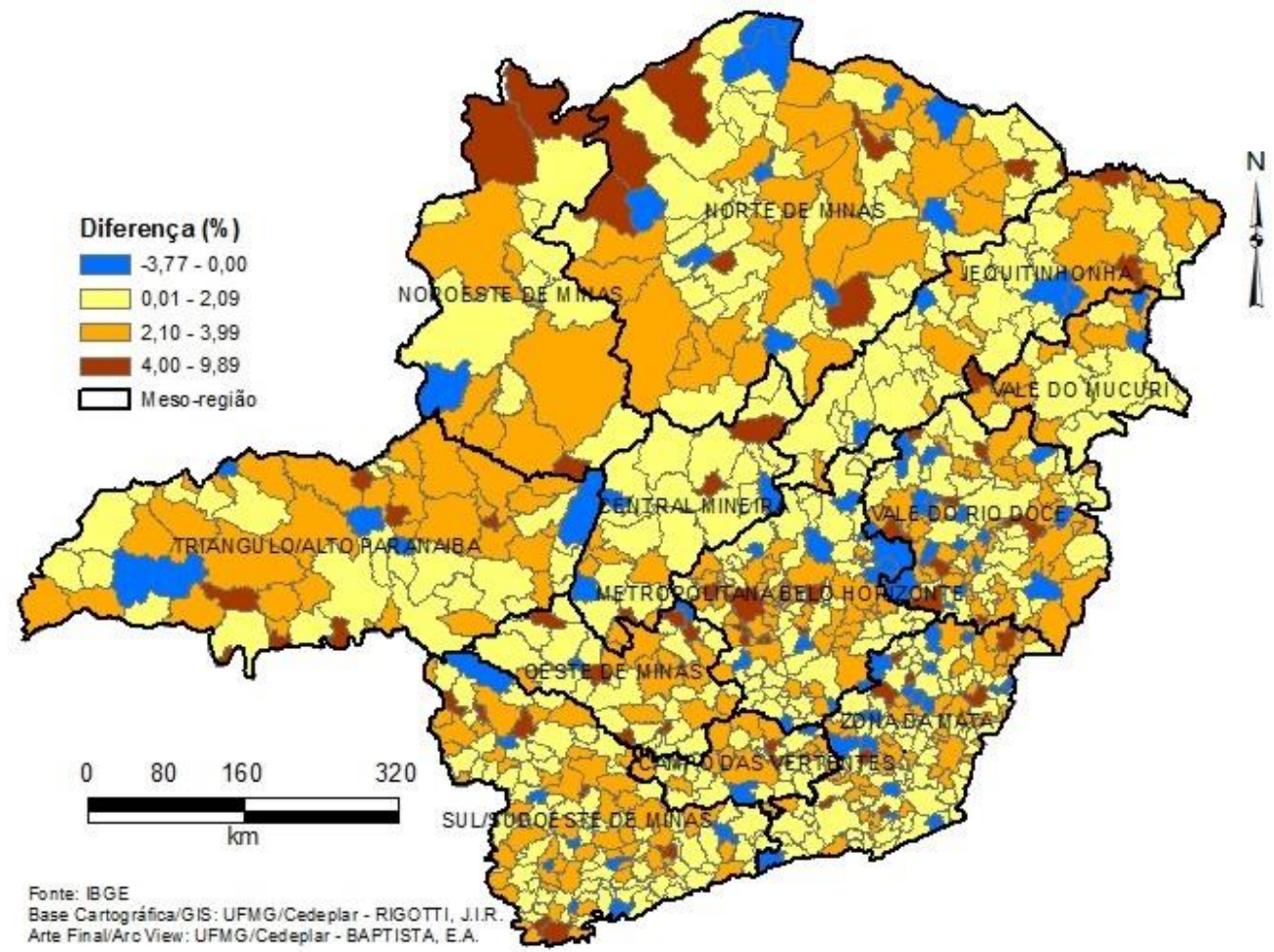

Figura 6: Diferença entre as Taxas Brutas Padronizadas de deficientes auditivos por município - Minas Gerais - 2010/2000 Fonte: Instituto Brasileiro de Geografia e Estatística (IBGE). Censos Demográficos de 2000 e 2010

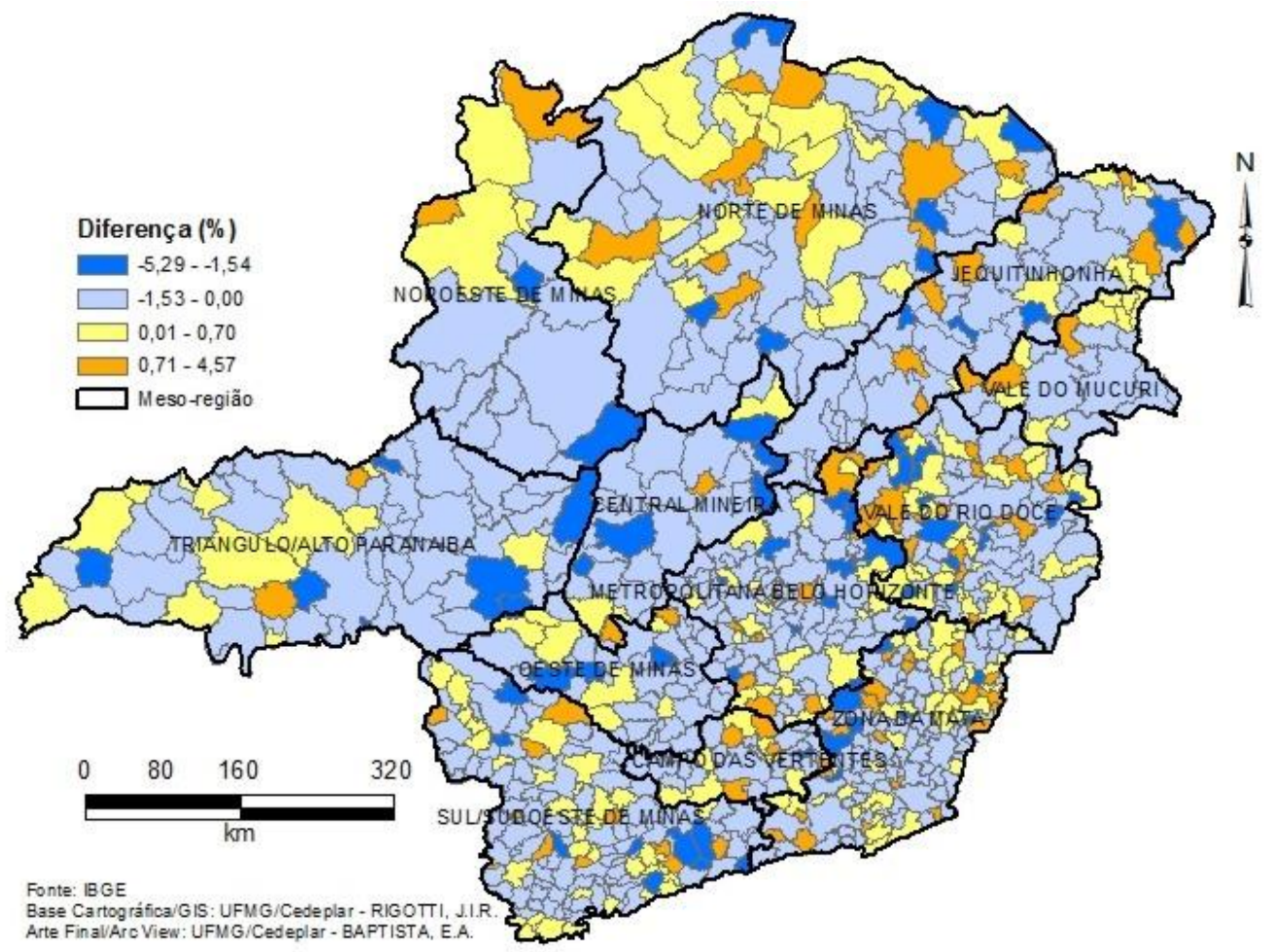

Figura 7: Diferença entre as Taxas Brutas Padronizadas de deficientes mentais por município - Minas Gerais - 2010/2000 Fonte: Instituto Brasileiro de Geografia e Estatística (IBGE). Censos Demográficos de 2000 e 2010 
As informações levantadas por este estudo revelaram ainda que um fato que permeia toda a discussão acerca dos deficientes no Estado de Minas Gerais é a questão da idade. Observou-se que o acúmulo de anos de vida traz consigo inúmeras limitações funcionais que, quando permanentes, traduzem-se em deficiências no sentido geral e em incapacidades, apesar dessas últimas sofrerem menor influência do processo natural de envelhecimento, acometendo indivíduos em fases distintas de sua vida. Além disso, uma interpretação aqui fundamentada é que os números derivados dos censos demográficos de 2000 e 2010, ao considerar pessoas com grande e/ou alguma dificuldade permanente de enxergar, ouvir e em capacidade de caminhar e subir escadas classificou grande parte da população idosa como tal. Entretanto, vale lembrar que o efeito da composição etária foi eliminado das variáveis em estudo através da técnica de padronização direta, tornando possível a avaliação dos níveis de deficiência.

No que tange a distribuição espacial da população deficiente examinada neste estudo, os mapas com as diferenças entre as taxas brutas padronizadas (figuras 3 a 7), por tipo de deficiência, não apresentaram padrões espaciais muito claros. Desta forma, e neste estudo em particular, a distribuição espacial não pareceu ser necessária para a compreensão do fenômeno em todas as facetas investigadas. Ainda assim, e mesmo que a distribuição espacial não tenha trazido "ganhos" para a análise, a manutenção da metodologia se faz de suma importância.
Este estudo procurou contribuir, especialmente no que tange o Estado de Minas Gerais, para que entidades públicas, privadas e sociedade de um modo geral possam ter informações confiáveis sobre esta população, orientando, assim, ações direcionadas a cada tipo de deficiência.

Espera-se que o poder público crie condições que possibilitem a inclusão social das pessoas deficientes por meio de políticas públicas. Na área de saúde, por exemplo, oferecer um atendimento especializado, incluindo programas de reeducação e reintegração que permita as pessoas com deficiência obter melhores desempenhos em suas atividades, sejam elas quais forem; linhas de crédito facilitadas para financiamento da casa própria, o que poderia beneficiar famílias pobres que possuem pessoas com deficiência; proporcionar capacitação e qualificação profissional a essa população, uma medida que deve ser vista como meta em todas as esferas de governo; investir fortemente em educação como forma de superar as desigualdades, os desníveis educacionais e os preconceitos existentes para com essa população; investir em acessibilidade, de modo a superar as barreiras criadas pelo homem. Todos estes pontos levantados, alinhavados com outros tantos, podem direcionar e conscientizar não somente a população deficiente, mas a sociedade como um todo. E é exatamente por pretender direcionar estes investimentos em políticas públicas de forma localizada e eficaz que este estudo se faz tão importante. 
Além disso, e sabendo-se da necessidade de ações e iniciativas de estudos mais detalhados sobre este grupo populacional relativamente escasso de informações e carente de ações públicas, acredita-se que este estudo poderá abrir um caminho, entre tantos necessários, para um maior conhecimento do universo das pessoas com deficiência, além de tentar plantar a semente de um maior interesse para novas questões sobre esta população.

\section{REFERÊNCIAS}

BAPTISTA, E.A. Os deficientes no Estado de Minas Gerais: uma abordagem espacial e demográfica utilizando os dados do Censo Demográfico de 2000 [dissertação]. Belo Horizonte (MG): Pontifícia Universidade Católica de Minas Gerais; 2009.

BRASIL. Decreto n. 3.298, de 20 dez. 1999. Regulamenta a Lei n. 7.853, de 24 de outubro de 1989. Diário Oficial, Brasília, 1999.

BRASIL. Ministério da Justiça. Relatório sobre a prevalência de deficiências, incapacidades e desvantagens. Niterói, Rio de Janeiro, 2004.

CARTA para o terceiro milênio. Disp. em: <http://www.cedipod.org.br/carta3m.doc>. Acesso em: 26 set. 2005.

CARVALHO, J.A.M.; SAWYER, D.O.; RODRIGUES, R.N. Introdução a alguns conceitos básicos e medidas em demografia. Belo Horizonte: Universidade Federal de Minas Gerais, 1994. 64 p. CORTELLA, M.S. O espaço da ética na relação indivíduo e sociedade. In: BONETTI, Dilséa A. et al. (orgs). Serviço Social e Ética: convite a uma nova práxis. São Paulo: Cortez/CFESS, 1996.

INSTITUTO BRASILEIRO DE GEOGRAFIA E ESTATÍSTICA. IBGE e CORDE abrem encontro internacional de estatísticas sobre pessoas com deficiência. Rio de Janeiro, 2005. Disponível em: <http://www.ibge.gov.br>. Acesso em: 22 set. 2005.

JANNUZZI, G.; JANNUZZI, N. Incidência de deficientes no Brasil segundo censo demográfico de 1991: resultados empíricos e implicações para políticas. In: ENCONTRO NACIONAL DE ESTUDOS POPULACIONAIS, 11, 1998. Anais... 1998. p. 2889-2908.

JENKS, G.F.; CASPALL, F.C. Error on choroplethic maps: definition, measurement, reduction. In: ANNALS OF THE ASSOCIATION OF AMERICAN GEOGRAPHERS, 1971, 217-244.

MEDEIROS, M.; DINIZ, D. A nova maneira de se entender a deficiência e o envelhecimento. Texto para Discussão, Brasília, n.1040, p. 3-18, set. 2004.

NERI, M.; SOARES, W. Idade, incapacidade e a inflação do número de pessoas com deficiência. In: CONGRESSO DA ASSOCIAÇÃO LATINO AMERICANA DE POPULAÇÃ̃, 1, 2004, Caxambu. Anais. 2004. p. 1-15.

SASSAKI, R.K. Inclusão - construindo uma sociedade para todos. Ed. WVA. Rio de Janeiro, 2002. 